\title{
DUAL EXPRESSION OF NEUROTRANSMITTER SYNTHESIS IN CULTURED AUTONOMIC NEURONS ${ }^{1}$
}

\author{
L. IACOVITTI, ${ }^{2}$ T. H. JOH,${ }^{*}$ D. H. PARK,${ }^{*}$ AND R. P. BUNGE \\ Department of Anatomy and Neurobiology, Washington University School of Medicine, St. Louis, Missouri 63110 and ${ }^{*}$ Cornell University \\ Medical College, New York, New York 10021
}

\begin{abstract}
Previous studies have demonstrated that, when the predominantly adrenergic neurons of the neonatal rat superior cervical ganglion (SCG) are grown under certain culture conditions, they acquire many of the properties characteristic of cholinergic neurons. To determine whether this occurs at the expense of certain of their adrenergic properties, cultured SCG neurons were characterized by both biochemical and immunocytochemical methods. We report here data which demonstrate that sympathetic neurons, cultured under conditions which foster the accrual of cholinergic properties, exhibit parallel increases in the activities and amounts of the specific adrenergic enzymes, tyrosine hydroxylase and dopamine $\beta$-hydroxylase, as well as the specific cholinergic enzyme, choline acetyltransferase. Using immunocytochemical methods, we further demonstrate that essentially all SCG neurons stain positively with antibodies to tyrosine hydroxylase, even at times in culture when choline acetyltransferase levels are elevated significantly. These data indicate that virtually all SCG neurons grown in our culture system are capable of dual neurotransmitter production and thus express at least the potential for dual function for up to 7 weeks in culture.
\end{abstract}

While it is thought that the neonatal rat superior cervical ganglion (SCG) is comprised predominantly of adrenergic neurons in vivo, a number of studies now have shown that these same neurons, under certain in vitro conditions, can acquire many of the characteristics of cholinergic neurons. These properties include: the development of choline acetyltransferase (CAT) activity (Patterson and Chun, 1974; M. Johnson et al., 1976; Ross et al., 1977; M. I. Johnson et al., 1980a, b), the acquisition of clear vesicles in synaptic terminals (M. Johnson et al., 1976; Landis, 1976; Ross et al., 1977; M. I. Johnson et al., $1980 \mathrm{a}, \mathrm{b})$, and the formation of nicotinic cholinergic synapses (O'Lague et al., 1974, 1978; M. Johnson et al., 1976; Ko et al., 1976; M. I. Johnson et al., 1980a, b; Wakshull et al., 1979). It has been established that these changes do not occur as a result of selection of neuronal subpopulations during the period in culture (for discussion, see Bunge et al., 1978; Patterson et al., 1978).

The finding that cultured SCG neurons express cholin-

\footnotetext{
' We are grateful to Dr. Eugene Johnson for providing facilities for the assay of enzymes and for his many helpful suggestions. We also thank Dr. Mary Johnson for helpful discussions and review of this manuscript. Expert laboratory assistance was provided by Lisa Wartels and Marcia Brodsky and secretarial assistance by Susan Mantia. This work was supported by National Institutes of Health Grants NB 11888 , NB 09923, and MH 24285.

${ }^{2}$ To whom correspondence should be addressed at Department of Anatomy and Neurobiology, Washington University School of Medicine, $660 \mathrm{~S}$. Euclid, St. Louis, MO 63110.
}

ergic properties may be interpreted in several ways. First, it is possible that individual SCG neurons are able to express stably only one transmitter system, either adrenergic or cholinergic, and that the acquisition of cholinergic traits in culture actually represents a shift in the cell's choice of transmitter production. Alternatively, it is possible that individual SCG neurons simultaneously develop both adrenergic and cholinergic transmitter-synthesizing mechanisms in culture, thereby, acquiring at least the potential for dual function.

Earlier studies (Patterson and Chun, 1974, 1977a, b; Patterson et al., 1976; Walicke et al., 1977), which showed that increases in cholinergic function may be accompanied by decreases in norepinephrine (NE) synthesis, were interpreted as being consistent with the concept that SCG neurons were able to express stably synthetic capacity for only one transmitter system. In these experiments, synthesis of NE and acetylcholine (ACh) was assessed by measuring the amounts of radiolabeled tyrosine and choline precursors which were incorporated into end products. In this assay, the amount of radiolabeled NE or ACh which was measured actually represented the end result in a number of cellular processes, including biosynthetic and degradative pathways. Because changes in any one step in these pathways may influence critically the amount of final product which is measured, a complete understanding of the processes involved requires analysis of individual metabolic steps.

Thus, in the present study, we sought to assess trans- 
mitter synthetic capacities directly by measuring, in the same cultures, the activities and amounts of the specific adrenergic enzymes, tyrosine hydroxylase (TH) and dopamine $\beta$-hydroxylase (DBH), as well as the specific cholinergic enzyme, CAT. We further examined, using immunocytochemical methods, the proportion of SCG neurons which continued to contain $\mathrm{TH}$ throughout their in vitro development. The results of these analyses indicate that individual SCG neurons do not lose NEsynthesizing capacity as ACh-synthesizing capacity increases. This finding is consistent with the second interpretation discussed above, i.e., that individual SCG neurons in our culture system have the potential for dual transmitter function.

\section{Materials and Methods}

Culture conditions. In these studies, dissociated sympathetic neurons were isolated from perinatal rats by previously described methods (Bunge et al., 1974). By twice exposing the cultures to feed containing the antimitotic agent, 5-fluorodeoxyuridine, and uridine, both at $10^{-5} \mathbf{M}$, we were able to grow the principal neurons of the SCG free of all other cell types for at least 2 months. Neurons were plated at a density of 2000 to 5000 neurons per dish on an air-dried collagen substratum and maintained in an atmosphere of $5 \% \mathrm{CO}_{2}$ at $35^{\circ} \mathrm{C}$ on media which contained $65 \%$ Eagle's minimum essential medium with added glutamine, $25 \%$ human placental serum, $10 \%$ chick embryo extract, $3 \% 1.1 \mathrm{~m}$ glucose, and nerve growth factor (25 units/ml prepared by the method of Bocchini and Angeletti (1969) and assayed according to the method of Varon et al. (1972)). Both human placental serum and chick embryo extract foster the development of cholinergic properties by SCG neurons in our culture system (C. D. Ross, M. I. Johnson, and R. P. Bunge, unpublished data).

Biochemical methods. Using a gridded dish, the number of neurons present in each culture was determined prior to biochemical analysis. At either 1, 3, 5, or 7 weeks in vitro, cultures were rinsed in Hank's balanced salt solution (without $\mathrm{Ca}^{2+}$ or $\mathrm{Mg}^{2+}$ ) and excess rinse was blotted carefully. Cultures, including collagen substratum, were dissected free of the culture dish, frozen on dry ice, and stored at $-80^{\circ} \mathrm{C}$. For all enzyme assays, tissues were homogenized in $5 \mathrm{~mm}$ Tris- $\mathrm{HCl}$ buffer, $\mathrm{pH}$ 7.4, containing $0.2 \%$ Triton $\mathrm{X}-100$ at a dilution that insured that the reaction was linear with enzyme concentration and time. The homogenate then was centrifuged at $10,000 \mathrm{rpm}$ for $10 \mathrm{~min}$ and the supernatant was decanted for enzyme assay. The activities of TH, DBH, and CAT were determined in the same tissue homogenate for each sample. TH was assayed by a modification of the method of Phillipson and Sandler (1975) in the presence of $40 \mu \mathrm{M}$ tyrosine and $625 \mu \mathrm{M} 6$-methyl-5,6,7,8-tetrahydropterine dihydrochloride and activity was expressed as femtomoles of dopa formed per neuron per hr. DBH activity was measured by the method of Henry et al. (1975) in the presence of $8 \mu \mathrm{M}$ copper sulfate and expressed as picomoles of octopamine formed per neuron per hr. CAT activity was measured by the method of Schrier and Shuster (1967) in the presence of $25 \mathrm{~mm}$ choline chloride and $10 \mu \mathrm{M}\left[{ }^{14} \mathrm{C}\right]$ acetylcoenzyme $\mathrm{A}$ and expressed as picomoles of $\mathrm{ACh}$ formed per neuron per $\mathrm{hr}$. To assure that we were measuring CAT and not the related enzyme carnitine acetyltransferase, representative cultures were incubated with $0.5 \mathrm{~mm}$ naphthylvinyl pyridine (NVP), a specific inhibitor of only CAT activity (White and Wu, 1973). In addition, all cultures were assayed in duplicate with and without a choline substrate. We found that both NVP and 0 choline blanks served as adequate controls, each inhibiting 95 to $100 \%$ of the total activity.

The immunochemical titration procedures, which utilized antibodies of established specificities, were performed by methods described previously (Joh et al., 1973; Reis et al., 1974; Wooten et al., 1978; Luine et al., 1980). In brief, tissues were homogenized in $10 \mathrm{~mm}$ potassium phosphate buffer, $\mathrm{pH} 7.0$, containing $0.2 \%$ Triton $\mathrm{X}-100$ and centrifuged at $10,000 \times g$ for $10 \mathrm{~min}$, and the supernatant was decanted for enzyme assay of TH and CA' activity. Tissue extract from 7-week-old cultures was diluted such that enzyme activity in an aliquot of diluted supernatant was identical to that in an equal volume of tissue extract from cultures grown 3 weeks in vitro. This required that the tissue extract from 7 -week-old cultures be diluted with buffer at a 1:2.5 dilution for $\mathrm{TH}$ and a 1: 3.7 dilution for CAT. Next, increasing amounts of specific antibodies were added to a fixed volume $(50 \mu l)$ of tissue extract and total volume was adjusted to $65 \mu \mathrm{l}$. The antigen/antibody mixture was allowed to stand for 60 min at room temperature for $\mathrm{TH}$ or overnight at $4^{\circ} \mathrm{C}$ for CAT with occasional shaking and then was centrifuged at $10,000 \times g$ for 10 min to remove the antigen - antibody complex. TH and CAT activities were determined in an aliquot of the supernatant according to previously described methods (Schrier and Shuster, 1967; Joh et al., 1973). As detailed above, specific CAT activity was determined using several kinds of controls.

Histological methods. Immunocytochemical staining procedures were adapted from a modification (Pickel et al., 1975) of the peroxidase-antiperoxidase method (Sternberger, 1974). Cultures were rinsed in Hank's balanced salt solution (without $\mathrm{Ca}^{2+}$ and $\mathrm{Mg}^{2+}$ ) and fixed in $4 \%$ paraformaldehyde in $0.1 \mathrm{M}$ phosphate buffer, $\mathrm{pH} 7.2$, for $20 \mathrm{~min}$. Cultures then were treated with specific antibodies to TH and the percentage of neurons which stained positively was determined. In each experiment, one of two controls for nonspecific staining was used. Either cultures of SCG neurons were processed with IgG isolated from pre-immune rabbit serum or cultures of tissues other than SCG neurons (Schwann cells, fibroblasts, heart cells, or dorsal root ganglion neurons) were treated with specific TH antibodies.

In addition, a number of attempts were made to localize CAT using variations of the same staining procedure. However, we were unable to stain reproducibly with CAT antibodies and the results of these experiments are not reported here.

\section{Results}

Our biochemical results derive from two experiments, each utilizing 100 cultures which were established from one group of fetuses and maintained in an identical manner. As depicted in Figure 1, the activities of $\mathrm{TH}$, 


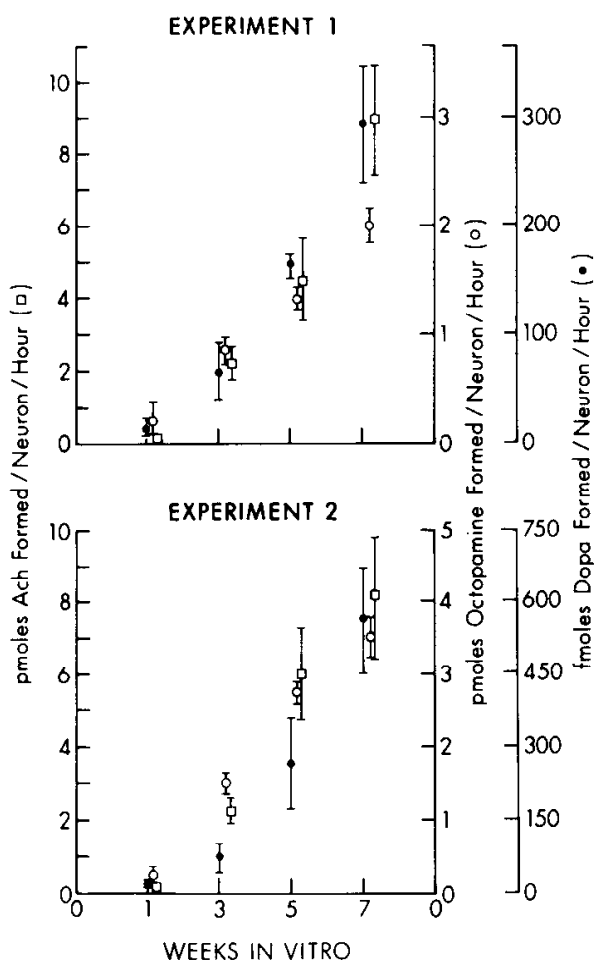

Figure 1. Time course of changes in TH, DBH, and CAT activities in cultures of dissociated perinatal rat SCG. Each experiment represents cultures derived from one group of fetuses and maintained in an identical manner. Each point represents the mean \pm SEM of five preparations. In experiments 1 and 2, CAT activity ( $\square$ ) increased in an identical manner, reaching levels of approximately $9 \mathrm{pmol}$ of $\mathrm{ACh} /$ neuron/hr by 7 weeks in culture. While the magnitude of the increases in the activities of $\mathrm{TH}(\mathrm{O})$ and $\mathrm{DBH}(\mathrm{O})$ remained the same for both experiments, the maximal levels of activity reached at 7 weeks in vitro differed in experiments 1 and 2 . The activity of all three enzymes in both experiments differed significantly between 3 and 7 weeks in vitro. In experiment 1 : for $\mathrm{TH}, p<0.05$; for $\mathrm{DBH}, p<0.001$; for CAT, $p<0.05$; in experiment 2 : for TH, $p$ $<0.05$; for DBH, $p<0.01$; and for CAT, $p<0.001$.

$\mathrm{DBH}$, and CAT were initially quite low in these cultures. However, with time in vitro, the activities of all three enzymes in both experiments rose in a synchronous and linear fashion with no sign of reaching a plateau even at 7 weeks. Between weeks 3 and 7, there was a 2.5- to 5fold increment in all three enzyme activities. To determine whether the increase in $\mathrm{TH}$ and CAT activities during this 4-week period was due to an increase in the numbers of enzyme molecules or rather due to activation of existing enzyme molecules, homogenates of cultured SCG neurons were titrated with specific antibodies to either TH or CAT (Fig. 2). When homogenates from SCG neurons grown 7 weeks in culture were diluted so that the enzyme activity in an aliquot of tissue extract was identical to that in an equal volume of tissue extract from cultures grown 3 weeks in vitro, immunochemical titration curves for both TH and CAT were overlapping. These data indicate that the increase in enzyme activity seen between weeks 3 and 7 in culture was due entirely to an increase in the number of TH and CAT molecules with no evident change in the catalytic state of the enzymes.
To determine whether individual neurons comprising the population of cultured neurons were developing exclusively either adrenergic or cholinergic mechanisms or whether, in fact, each individual neuron was capable of dual transmitter synthesis, sister cultures were stained with specific antibodies to $\mathrm{TH}$ and the proportion of neurons which stained positively was determined. Cultures processed with IgG from pre-immune rabbit serum served as controls. As shown in Figure $3 D$, only low levels of background staining were found in these cultures. Similarly, cultures of tissues other than SCG (Schwann cells, fibroblasts, heart cells, and dorsal root ganglion neurons) (data not shown) also stained very lightly when reacted with $\mathrm{TH}$ antibodies, especially when compared with the specific dark brown staining reaction found in the perikarya (not in the nucleus) (Fig. $4 A$ ) and in the processes (Fig. $4 B$ ) of SCG neurons treated similarly. When examined at 2,4 , or 7 weeks in vitro (Fig. $3, A, B$, and $C$ ), 95 to $99 \%$ of all SCG neurons were found to stain positively with antibodies to TH. Note that there were no apparent differences in the intensity of staining with relation to age in culture (cf., Fig. $3, A, B$, and $C$ ). Thus, the proportion of neurons containing $\mathrm{TH}$ and the intensity of the staining reaction for $\mathrm{TH}$ did not increase during a time when $\mathrm{TH}$ protein underwent a marked increment. One possible explanation for this apparent contradiction is that $\mathrm{TH}$ concentration per unit volume of neuronal cytoplasm may remain the same even though total cytoplasmic volume increases with time in culture. The increasing numbers of neuronal processes which are seen with increasing age in culture (cf., Fig. $3, A, B$, and $C)$ are consistent with this idea. However, since the conditions which insure the linearity of the staining reaction were not determined beforehand, it is possible that the immunocytochemical procedure used in this study did not provide a quantitative measure of enzyme concentration.

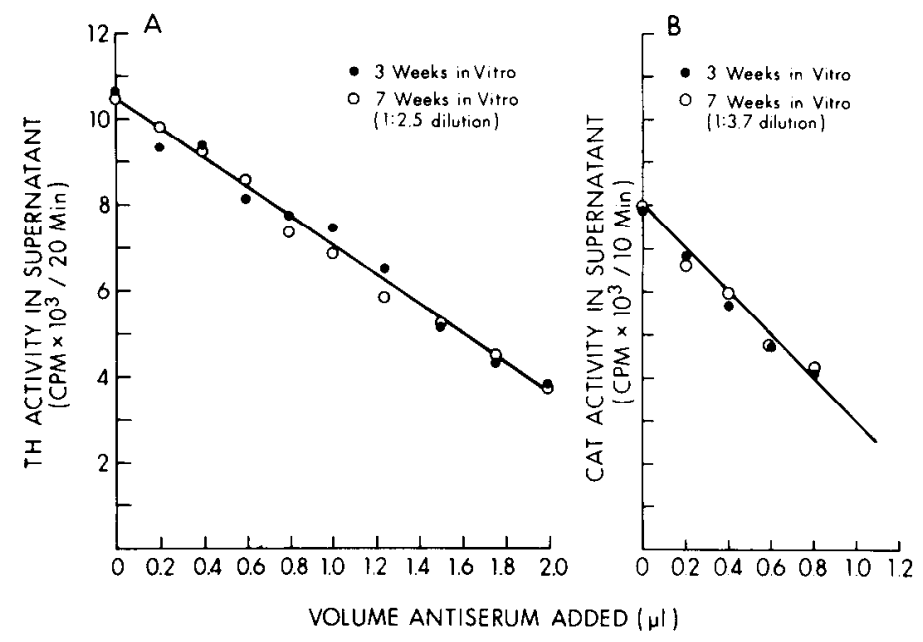

Figure 2. Immunochemical titration curves of $(A) \mathrm{TH}$ and $(B) \mathrm{CAT}$ in homogenates of SCG neurons grown $3(O)$ or 7 (O) weeks in culture. Note that the immunochemical titration curves for both TH and CAT are overlapping, indicating that the increase in $\mathrm{TH}$ and CAT enzyme activities found between weeks 3 and 7 in vitro is due to an increase in the number of specific enzyme molecules. 


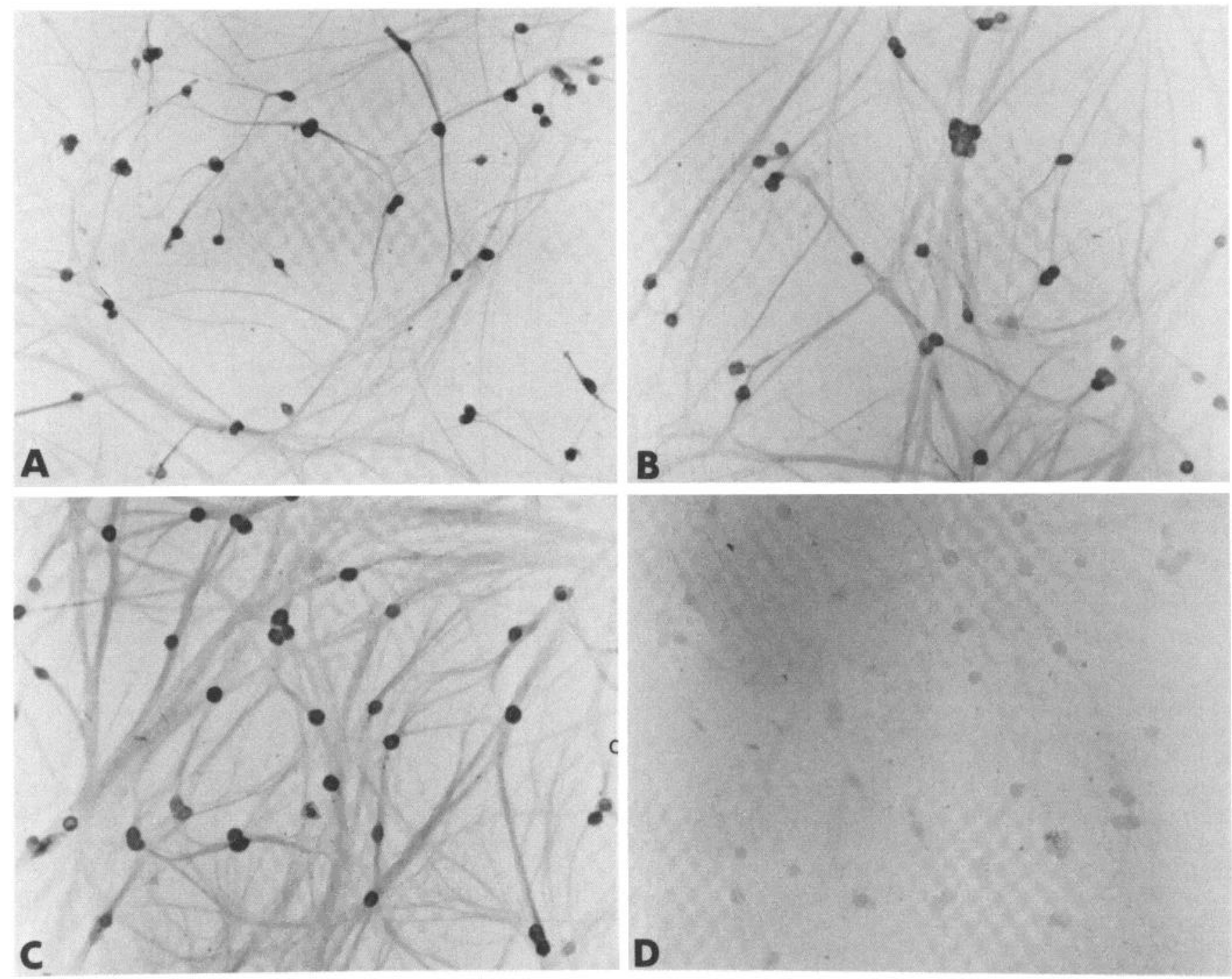

Figure 3. Immunocytochemical localization of TH in SCG neurons using the peroxidase-antiperoxidase method (Sternberger, 1974). At $(A) 2$ weeks, $(B) 4$ weeks, or $(C) 7$ weeks in vitro, cultures were rinsed in Hank's balanced salt solution and stained with specific antisera to TH. Sister cultures stained with IgG isolated from pre-immune rabbit sera $(D)$ served as controls in each experiment. In addition, negative staining with antisera to TH in cultures of either dorsal root ganglion cells, Schwann cells, fibroblasts, or heart cells (not shown here) also served as controls for nonspecific staining. The above cultures were photographed at the same magnification $(\times 4)$.

\section{Discussion}

Whereas earlier studies (M. Johnson et al., 1976; Ross et al., 1977; M. I. Johnson et al., 1980a, b) have reported increases in CAT activity of similar magnitude to those reported here (as well as acetylcholinesterase), the only index of adrenergic enzyme function in these studies was measurement of the activity of the relatively nonspecific enzyme, dopa decarboxylase (DDC). We now have demonstrated that the activities and amounts of the ratelimiting enzyme (TH) and the final enzyme (DBH) in the NE biosynthetic pathway increase in parallel with both those of the ACh-synthesizing enzyme, CAT, and those reported for DDC (M. I. Johnson et al., 1980a, b).

Furthermore, the present study provides immunocytochemical evidence that virtually all cultured SCG neurons contain $\mathrm{TH}$ for up to 7 weeks in vitro. Taken together with the biochemical demonstration of CAT enzyme accrual and with data derived from physiological studies showing that up to $90 \%$ of neurons identified as cholinergic "drivers" also contain TH in their cytoplasm (Higgins et al., 1981), the findings from the present study suggest that essentially all individual neurons comprising the SCG population in our culture dishes express the simultaneous capacity for both NE and ACh synthesis in culture.

While several prior studies of the SCG neuron in vitro also have reported the existence of neurons which were dual function, these studies did not establish whether this represented a transient phase preceding the neurons actual "shift" from adrenergic to cholinergic function or rather the permanent condition of this neuron in culture. Reichardt and Patterson (1977), measuring the capacity of intact individual neurons to synthesize NE (from tyrosine) or ACh (from choline), found simultaneous synthesis of NE and $\mathrm{ACh}$ in only two cases, although all 


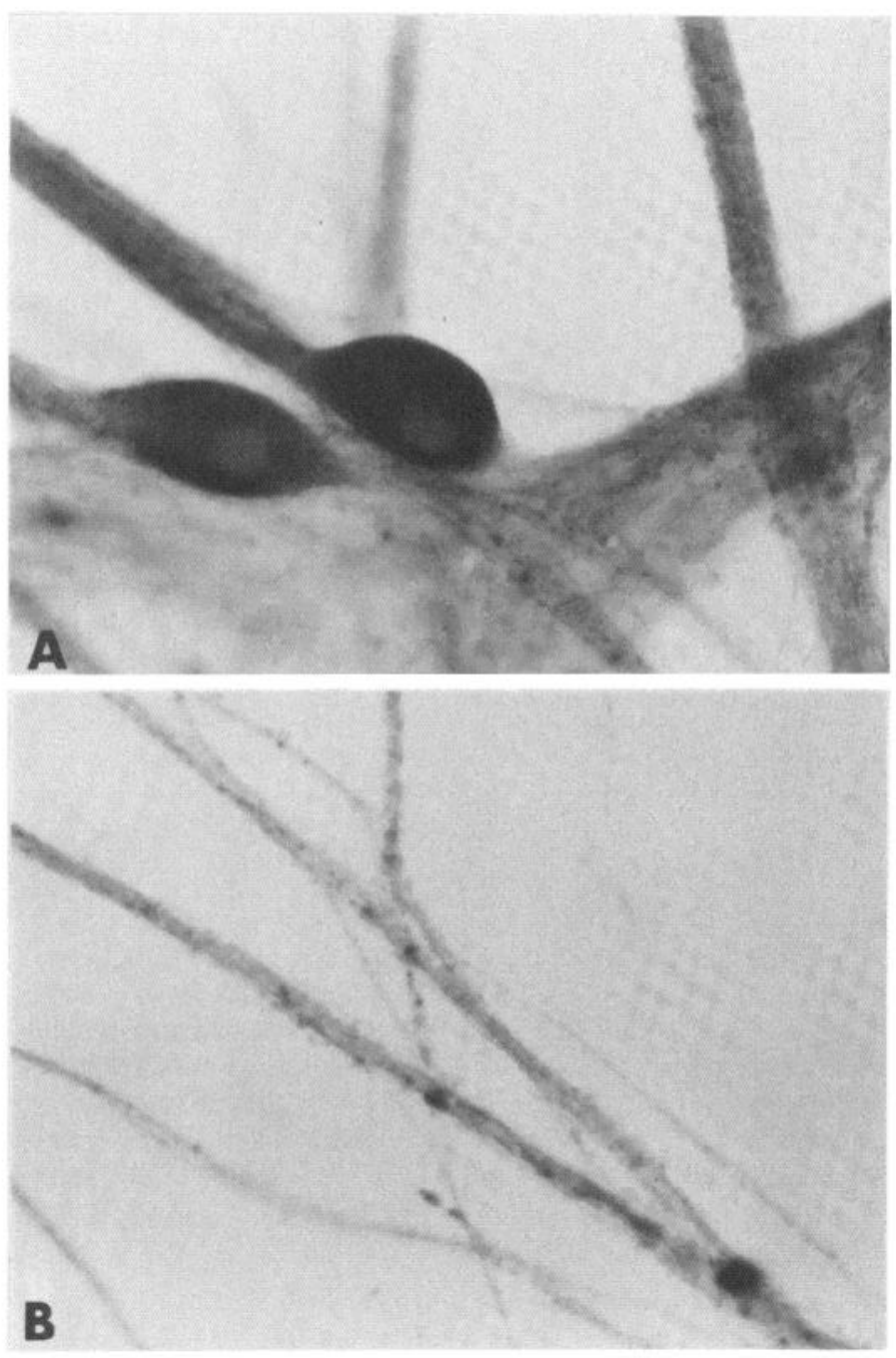

Figure 4. Immunocytochemical demonstration of $\mathrm{TH}$ in the $(A)$ perikarya of neurons grown 6 weeks in culture and $(B)$ neuronal processes of SCG neurons grown 4 weeks in vitro. Note the abundance of specific dark reaction particles throughout the neuronal cytoplasm with the exception of the nucleus. Both $A$ and $B$ were photographed at $\times 25$ magnification.

neurons, including those which synthesize only $\mathrm{ACh}$, retained their uptake mechanisms for NE. On this basis, these authors suggested that the number of neurotransmitters made by most mature individual neurons in their culture system was restricted. The apparent discrepancy between these earlier findings and those reported here may result from differences in culture conditions or in assay methods.

Additional studies by Furshpan et al. (1976), utilizing a very sensitive test system in which transmitter release capacity of single neurons was measured physiologically, found that, under specific culture conditions, a certain number of neurons could release both $\mathrm{NE}$ and $\mathrm{ACh}$. In these experiments, however, a single neuron was not followed through a dual function state to a subsequent stage of single transmitter production, and therefore, the question of whether the dual functional state persisted was left open. Under the culture conditions reported in the present study and in a recent study by Higgins et al.
(1981), the capacity for dual transmitter production was found to persist for at least 7 weeks in vitro.

Earlier reports from our laboratory (M. Johnson et al., 1976; Ross et al., 1977; M. I. Johnson et al., 1980a, b) and others (Landis, 1976, 1980) have found that, as cholinergic function increases in culture, synaptic profiles contain fewer vesicles with dense cores (i.e., adrenergic) and display increasingly greater proportions of synaptic vesicles with "clear" (i.e., cholinergic) morphology. Since the present results demonstrate that, during this same time in culture, adrenergic enzyme activity continues to increase, it is somewhat puzzling that vesicles should lose their dense cores. Several possible explanations are being considered: (1) that while these neurons contain the enzymatic machinery needed to produce NE, they, in fact, do not manufacture end product; preliminary studies, however, indicate that endogenous levels of NE increase at least 5 -fold between weeks 1 and 7 in culture (L. Iacovitti, unpublished data); (2) that NE and ACh coexist within the same synaptic vesicles but that, under these conditions, cytochemical reaction for $\mathrm{NE}$ no longer results in the demonstration of a dense core; or (3) that, while NE and ACh may both be manufactured in these cells, cholinergic mechanisms compete more successfully in the vesicle loading process. Distinguishing between these possibilities awaits further study of the mechanisms of vesicle loading in neurons exhibiting both adrenergic and cholinergic properties.

Thus, the findings from the present study on populations of cultured SCG neurons, taken together with the previous demonstration that up to $90 \%$ of individual SCG neurons both release $\mathrm{ACh}$ and contain $\mathrm{TH}$ (Higgins et al., 1981), strongly suggest that these cells are not abandoning their adrenergic phenotype in order to adopt a cholinergic one but rather that essentially all of these neurons express the simultaneous capacity for dual transmitter synthesis. Since this capacity is not lost even at 7 weeks in vitro, the potential for dual function in SCG neurons appears to be a persistent rather than a transient property. Finally, it should be noted that neural crest cells destined to become catecholaminergic cells in the developing embryo may, if provided with an alternate site of residence, express cholinergic characteristics (for discussion, see Le Douarin, 1980). Thus, the neuronal properties evident from these in vitro observations also may be expressed, at least in part, in vivo.

\section{References}

Bocchini, V., and P. Angeletti (1969) The nerve growth factor: Purification as a 30,000-molecular weight protein. Proc. Natl Acad. Sci. U. S. A. 64: 787-794.

Bunge, R. P., R. Rees, P. Wood, H. Burton, and C. -P. Ko (1974) Anatomical and physiological observation on synapses formed on isolated autonomic neurons in tissue culture. Brain Res. 66: 401-412.

Bunge, R. P., M. Johnson, and C. D. Ross (1978) Nature and nurture in the development of the autonomic neuron. Science 199: 1409-1416.

Furshpan, E. J., P. R. Macleish, P. H. O'Lague, and D. D. Potter (1976) Chemical transmission between rat sympathetic neurons and cardiac myocytes developing in microcultures: Evidence for cholinergic, adrenergic, and dual-function neurons. Proc. Nati. Acad. Sci. U. S. A. 73: 4225-4229. 
Henry, D. P., D. B. Johnson, B. J. Starman, and R. H. Williams (1975) Kinetic characterization of rat serum dopamine-betahydroxylase using a simplified radioenzymatic assay. Life Sci. 17: 1179-1186.

Higgins, D., L. Iacovitti, T. H. Joh, and H. Burton (1981) The immunocytochemical localization of tyrosine hydroxylase within rat sympathetic neurons that release acetylcholine in culture. J. Neurosci. 1: 126-131.

Joh, T. H., C. Geghman, and D. J. Reis (1973) Immunochemical demonstration of increased accumulation of tyrosine hydroxylase protein in sympathetic ganglia and adrenal medulla elicited by reserpine. Proc. Natl. Acad. Sci. U. S. A. 70: 27672771 .

Johnson, M., D. Ross, M. Meyers, R. Rees, R. Bunge, E. Wakshull, and H. Burton (1976) Synaptic vesicle cytochemistry changes when cultured sympathetic neurons develop cholinergic interactions. Nature 262: 308-310.

Johnson, M. I., C. D. Ross, E. Meyers, L. Spitznagel, and R. P. Bunge (1980a) Morphological and biochemical studies on the development of cholinergic properties in cultured sympathetic neurons. I. Correlative changes in choline acetyltransferase and synaptic vesicle cytochemistry. J. Cell Biol. 84: $680-691$.

Johnson, M. I., C. D. Ross, and R. P. Bunge (1980b) Morphological and biochemical studies on the development of cholinergic properties in cultured sympathetic neurons. II. Dependence on postnatal age. J. Cell Biol. 84: 692-704.

Ko, C. -P., H. Burton, M. I. Johnson, and R. P. Bunge (1976) Synaptic transmission between rat superior cervical ganglion neurons in dissociated cell cultures. Brain Res. 117: 461-485.

Landis, S. C. (1976) Rat sympathetic neurons and cardiac myocytes developing in microcultures: Correlation of fine structure of endings with neurotransmitter function in single neurons. Proc. Natl. Acad. Sci. U. S. A. 73: 4220-4224.

Landis, S. C. (1980) Developmental changes in the neurotransmitter properties of dissociated sympathetic neurons: A cytochemical study of the effects of medium. Dev. Biol. 77: 349-361.

Le Douarin, N. M. (1980) The ontogeny of the neural crest in avian embryo chimeras. Nature 286: 663-669.

Luine, V. N., D. H. Park, T. H. Joh, D. J. Reis, and B. S. McEwen (1980) Immunochemical demonstration of increased choline acetyltransferase concentration in rat preoptic area after estradiol administration. Brain Res. 191: 273-277.

O'Lague, P. H., K. Obata, P. Claude, E. J. Furshpan, and D. D. Potter (1974) Evidence for cholinergic synapses between dissociated rat sympathetic neuron in cell culture. Proc. Natl. Acad. Sci. U. S. A. 71: 3602-3606.

O'Lague, P. H., E. J. Furshpan, and D. D. Potter (1978) Studies on rat sympathetic neurons developing in cell culture. II. Synaptic mechanisms. Dev. Biol. 67: 404-423.

Patterson, P. H., and L. L. Y. Chun (1974) The influence of nonneuronal cells on catecholamine and acetylcholine synthesis and accumulation in cultures of dissociated sympa- thetic neurons. Proc. Natl. Acad. Sci. U. S. A. 71: 3607-3610. Patterson, P. H., and L. L. Y. Chun (1977a) The induction of acetylcholine synthesis in primary cultures of dissociated rat sympathetic neurons. I. Effects of conditioned medium. Dev. Biol. 56: 263-280.

Patterson, P. H., and L. L. Y. Chun (1977b) The induction of acetylcholine synthesis in primary cultures of dissociated rat sympathetic neurons. II. Developmental aspects. Dev. Biol. 60: 473-481.

Patterson, P. H., L. F. Reichardt, and L. L. Y. Chun (1976) Biochemical studies on the development of primary sympathetic neurons in cell culture. Cold Spring Harbor Symp. Quant. Biol. 40: 389-397.

Patterson, P. H., D. D. Potter, and E. J. Furshpan (1978) The chemical differentiation of nerve cells. Sci. Am. 239: 50-59.

Phillipson, O. J., and M. Sandler (1975) The effect of hydrocortisone and adrenocorticotrophic hormones on monamine oxidase and tyrosine hydroxylase in explant cultures of embryonic chick sympathetic ganglia. Brain Res. 90: 283-296.

Pickel, V. M., T. H. Joh, P. M. Field, C. G. Becker, and D. J. Reis (1975) Cellular localization of tyrosine hydroxylase by immunohistochemistry. J. Histochem. Cytochem. 23: 1-12.

Reichardt, L. F., and P. H. Patterson (1977) Neurotransmitter synthesis and uptake by isolated sympathetic neurons in microcultures. Nature 270: 147-151.

Reis, D. J., T. H. Joh, R. A. Ross, and V. M. Pickel (1974) Reserpine selectively increases tyrosine hydroxylase and dopamine- $\beta$-hydroxylase enzyme protein in central noradrenergic neurons. Brain Res. 81: 380-386.

Ross, D., M. I. Johnson, and R. P. Bunge (1977) Development of cholinergic characteristics in adrenergic neurones is age dependent. Nature 267: 536-539.

Schrier, B. K., and L. Shuster (1967) A simplified radiochemical assay for choline acetyltransferase. J. Neurochem. 14: 977985.

Sternberger, L. A. (1974) Immunocytochemistry, Prentice-Hall, Inc., Englewood Cliffs, NJ.

Varon, S., J. Nomura, J. Perez-Polo, and E. Shooter (1972) Isolation and assay of nerve growth factor. In Methods of Neurochemistry, R. Fried, ed., Marcel Dekker, Inc., New York.

Wakshull, E., M. I. Johnson, and H. Burton (1979) Studies of postnatal rat sympathetic neurons in culture. I. A comparison with embryonic neurons. J. Neurophysiol. 42: 1410-1425.

Walicke, P. A., R. B. Campenot, and P. H. Patterson (1977) Determination of transmitter function by neuronal activity. Proc. Natl. Acad. Sci. U. S. A. 74: 5767-5771.

White, H. L., and J. C. Wu (1973) Choline and carnitine acetyltransferases. Biochemistry 12: 841-846.

Wooten, G. F., D. H. Park, T. H. Joh, and D. J. Reis (1978) Immunochemical demonstration of reversible reduction in choline acetyltransferase concentration in rat hypoglossal nucleus after hypoglossal nerve transection. Nature 275: 324325 . 